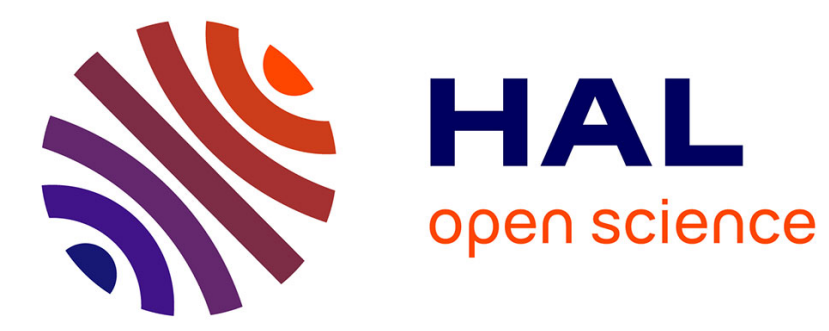

\title{
Semi-Empirical Modelling of Erosion Phenomena for Ice Crystal Icing Numerical Simulation
}

\author{
Virgile Charton, Pierre Trontin, Gilles Aouizerate, Philippe Villedieu
}

\section{To cite this version:}

Virgile Charton, Pierre Trontin, Gilles Aouizerate, Philippe Villedieu. Semi-Empirical Modelling of Erosion Phenomena for Ice Crystal Icing Numerical Simulation. SAE International journal of advances and current practices in mobility, 2019, 10.4271/2019-01-1967 . hal-02781029

\section{HAL Id: hal-02781029 \\ https://hal.science/hal-02781029}

Submitted on 4 Jun 2020

HAL is a multi-disciplinary open access archive for the deposit and dissemination of scientific research documents, whether they are published or not. The documents may come from teaching and research institutions in France or abroad, or from public or private research centers.
L'archive ouverte pluridisciplinaire HAL, est destinée au dépôt et à la diffusion de documents scientifiques de niveau recherche, publiés ou non, émanant des établissements d'enseignement et de recherche français ou étrangers, des laboratoires publics ou privés. 


\title{
Semi-empirical modelling of erosion phenomena for ice crystal icing numerical simulation
}

\author{
Virgile Charton, Pierre Trontin, Gilles Aouizerate, Philippe Villedieu
}

\begin{abstract}
The aim of this work is to develop a semi-empirical model for erosion phenomena under ice crystal condition, which is one of the major phenomena for ice crystal accretion. Such a model would be able to calculate the erosion rate caused by impinging ice crystals on accreted ice layer.
\end{abstract}

This model is based on Finnie [1] and Bitter [2] [3] solid/solid collision theory which assumes that metal erosion due to sand impingement is driven by two phenomena: cutting wear and deformation wear. These two phenomena are strongly dependent on the particle density, velocity and shape, as well as on the surface physical properties such as Young modulus, Poisson ratio, surface yield strength and hardness. Moreover, cutting wear is mostly driven by tangential velocity and is more effective for ductile eroded body, whereas deformation wear is driven by normal velocity and is more effective for brittle eroded body. Several researchers based their erosion modelling on these two phenomena such as Hutchings et al. [4] for deformation erosion, or Huang et al. [5] and Arabnejad et al. [6] for cutting and deformation erosion.

The main work of this paper is to develop an erosion model for ice crystal impingement based on these two phenomena, and to show its capability to predict accretion shape by simulating experimental cases from the National Research Council of Canada (NRC). NRC's Currie et al. ice crystal experiments [7] [8] realized in warm aerodynamic conditions, such as the one encountered in high icing severity areas of a turbofan engine, show accretion severity for a large range of liquid water content to total water content. In order to validate the erosion model based on solid/solid collision, this paper presents the simulation of the lower melting rate experiment. Results show fair agreement with experimental data and allow us to propose pertinent further work.

\section{Introduction}

Aircraft icing is studied since the early $20^{\text {th }}$ century, as it is a major weather hazard for aircraft operation. During the $90 \mathrm{~s}$, ice crystal icing has been identified [9], and the regulation accordingly modified. The mechanisms involved in ice crystal icing are not fully understood and several ongoing projects such as MUSIC-Haic [10] are still needed to improve the knowledge on ice crystal icing and to build robust modelling tools able to predict the location and the severity of the accretion.

A major phenomenon that drives ice crystal icing is the erosion caused by impinging crystals on accreted ice deposits. For now, empirical models are used to calculate the erosion rate as the one proposed by Trontin et al. [11] [12] in Onera's 2D icing code based on Currie et al. experimentations [8] [7]. These empirical models were developed with few experimental data, and even if they have good agreement with the data used for their calibration, it can't be assumed that they will be able to predict well ice accretion size and shape for new experimental cases. The objective of this paper is to

Page 1 of 8 study if a model backed by solid-solid erosion can be proposed. Such a model should be more reliable for the simulation of new cases.

The first part of this paper briefly introduces the existing erosion model implemented in Onera's 2D icing code IGLOO2D, and highlights the improvements needed. The second part of this paper is dedicated to solid/solid collision theory, which allows us to calculate the volume eroded by the two identified mechanisms: deformation wear and cutting wear. The third part presents simulation results and discussion around them, especially compared to IGLOO2D ones. Finally the last part introduces future work, in particular the particle size and the liquid water dependencies.

\section{Onera's 2D icing code erosion modelling}

IGLOO2D icing code takes into account the influence of erosion phenomenon on ice shape by calculating an erosion rate which corrects the accretion rate given by mass and energy balance equations (IGLOO2D extended Messinger's equations are presented in [11]).

Erosion means here material loss caused by crystals impact on ice layer. During the framework of High Altitude Ice Crystal project (HAIC) [13] Trontin et al. [11] [12] developed an empirical model based on Currie et al. [8] [7] observations in order to calculate this material loss. This model gives the erosion rate $\dot{m}_{e r}$ as:

$$
\dot{m}_{e r}=\eta_{e r} \times \dot{m}_{i m p}
$$

Where $\dot{m}_{i m p}$ is the impacting mass rate and $\eta_{e r}$ the erosion ratio. HAIC erosion model gives a value of $\eta_{e r}$, between 0 and 1 , according to:

$$
\eta_{e r}=E\left(\frac{V_{t}}{V_{0}}\right)^{2}\left(\frac{\alpha_{l 0}}{\alpha_{l 0}-\min \left(\alpha_{l}, \alpha_{l 0}\right)}\right)\left(1+\left(l_{0} k\right)^{2}\right)
$$

Where $V_{t}$ is the tangential impact velocity, $\alpha_{l}$ the wall liquid ratio, and $k$ the wall curvature. $E, V_{0}, \alpha_{l 0}$ and $l_{0}$ are empirical parameters only calibrated on Currie's experiment. One can notice that the velocity dependency is linked to the tangential component only, which means that negligible erosion should be predicted for quasinormal impact. Also the curvature term is a numerical correction which reflects the smoothing effect of erosion phenomenon. The new model presented furtherly is aimed at reducing the empiricism of the original one by giving more physical meaning to the adjustable parameters. In addition, it is expected to have a larger domain of validity.

\section{Semi-empirical erosion modelling}

This section presents the semi-empirical erosion model inspired by Finnie [1] and Bitter [2] [3] solid-solid collision theory. According to these authors, erosion phenomenon caused by a solid particle impact on a wall is mainly due to two phenomena: the deformation wear and the cutting wear. For the sake of simplification, and because 
experimental data are better exploitable in 2 dimensions, the following sections will use a $2 \mathrm{D}$ approach. However, the semiempirical model developed in this paper can be implemented in $3 \mathrm{D}$ simulation codes as well as in 2D's ones.

\section{Deformation wear}

According to Bitter [2], deformation wear is the consequence of the particle kinetic energy that is absorbed by the body during the impact. As long as the maximum corresponding stress, which occurs on the center of the contact area, does not reach the yield strength of the material, only elastic deformation occurs and no material is removed. However, if the yield strength is exceeded during the collision, plastic deformation happens at the place of maximum stress. Hence, a large number of particle impacts will form a plastically deformed surface with an increased hardness that may lead to material failure due to the creation of lateral and radial cracks [13] (Figure 1).

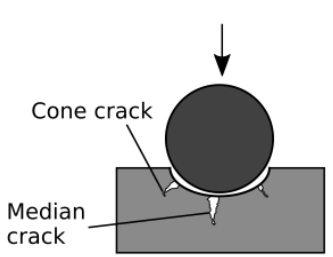

(a)

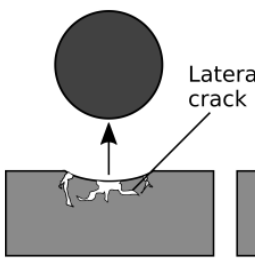

(b)

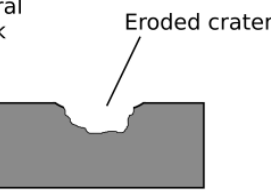

(c)
Figure 1: Expected mechanism of deformation erosion - (a) growth of cone crack and median crack, (b) closure of median cracks and creaction of lateral cracks, (c) eroded crater formed Adapted from Parsi et al. [13]

The eroded volume is calculated resolving energy balance equation using the following assumptions:

1) Impinging particles are spherical

2) No particle fragmentation or plastic deformation occurs within the particle

3) Impact velocity is low enough, so that the energy dissipated as heat is negligible

4) The eroded volume is equivalent to the volume of the formed crater

For elastic-plastic impact, the provided kinetic energy is divided into three energies absorbed in the substrate (Figure 2):

$$
Q=\frac{1}{2} m V_{n}^{2}=Q_{e}+Q_{p e}+Q_{p}
$$

Where $Q$ is the kinetic energy, $Q_{e}$ the energy absorbed in the region of elastic deformation, $Q_{p e}$ the potential energy of the elastic deformation in the area subjected to a plastic-elastic load, and $Q_{p}$ the energy required to the formation of the permanent indentation.

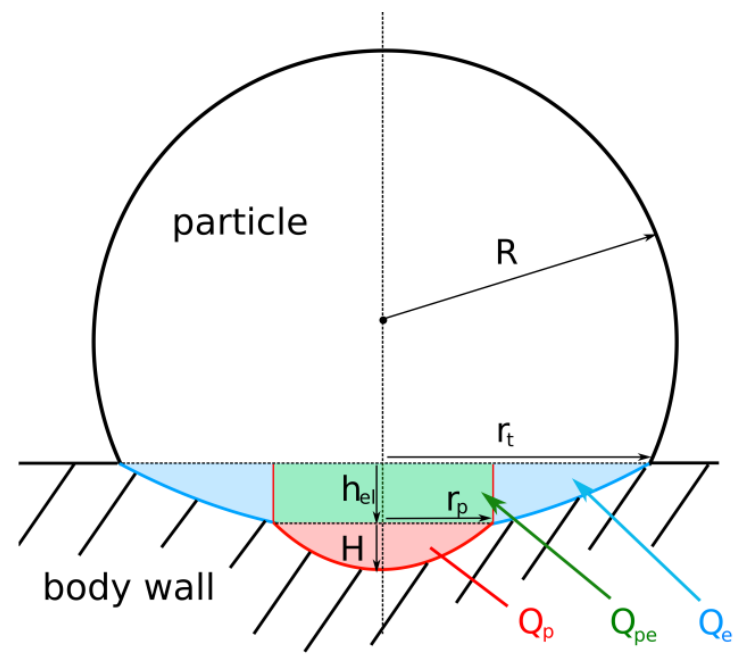

Figure 2: Deformation erosion energy balance - The kinetic energy is divided into $Q_{e}$ (blue area), $Q_{p e}$ (green area) and $Q_{p}$ (red area)

In the case of an elastic-plastic impact, the energy $Q_{e}$ absorbed in the region of elastic deformation corresponds to the amount of kinetic energy absorbed with a velocity $V_{e l}$ at which the elastic limit is just reached:

$$
Q_{e}=\frac{1}{2} m V_{e l}^{2}
$$

Where $m$ is the particle mass. The elastic velocity $V_{e l}$ is expressed using Hertz elastic collision theory [2]:

$$
V_{e l}=\frac{\pi^{2}}{2 \sqrt{10 \rho}} R_{e l}^{\frac{5}{2}}\left(\frac{1-q_{\text {sub }}^{2}}{E_{\text {sub }}}+\frac{1-q_{\text {part }}^{2}}{E_{\text {part }}}\right)^{2}
$$

Where $\rho$ is the particle density, $R_{e l}$, called yield strength (or elastic limit), is the largest load that can be exerted upon the body without causing plastic deformation, $q$ and $E$ are respectively Poisson's ratio and Young's modulus of particle (part) and substrate (sub).

$Q_{p e}$ is the potential energy of the elastic deformation in the area subjected to the elastic-plastic load (green area), whereas $Q_{p}$ is the energy of the plastic deformation (red area). Using the definition of the potential energy, one has:

$$
Q_{p e}=\int_{0}^{h_{e l}} \vec{F} \cdot \overrightarrow{d h}
$$

Where $F=\frac{1}{2} R_{e l} \pi r_{p}^{2}$ is the average force applied during the impact (at the beginning of the impact, the pressure is null and when the elastic limit is reached, the impact pressure is equal to $\left.R_{e l}\right)$. Using the Pythagorean theorem and assuming a small depth of indentation, the following geometrical relation between the elastic-plastic contact area radius $r_{p}$, the indentation depth $H$ and the particle radius $R$ can be written:

$$
r_{p}^{2}=2 R H
$$

Consequently, this leads to:

Page 2 of 8 


$$
Q_{p e}=\int_{0}^{h_{e l}} \frac{1}{2} R_{e l} \pi r_{p}^{2} d h_{e l}=\int_{0}^{h_{e l}} R_{e l} \pi R H d h_{e l}=R_{e l} \pi R H h_{e l}
$$

Similarly, one can express $Q_{p}$ with $F=R_{e l} \pi r_{p}^{2}$ (elastic limit is already reached):

$$
Q_{p}=\int_{0}^{H} R_{e l} \pi r_{p}^{2} d H=\int_{0}^{h_{e l}} R_{e l} \pi 2 R H d H=R_{e l} \pi R H^{2}
$$

Using the following relation between $V_{e l}$ and $h_{e l}$ from the Hertzian theory [2]:

$$
R h_{e l}^{2}=\frac{15}{8} \frac{m}{\pi R_{e l}} V_{e l}^{2}
$$

The previous expression of the energies involved imply:

$$
Q_{p e}=R_{e l} \pi R H h_{e l}=\sqrt{\pi R_{e l} R h_{e l}^{2}} \sqrt{\pi R_{e l} R H^{2}}=\sqrt{\frac{15}{4} Q_{e} Q_{p}}
$$

Finally, using the energy balance equation (3):

$$
Q=Q_{e}+\sqrt{\frac{15}{4} Q_{e} Q_{p}}+Q_{p}=\left(\sqrt{Q_{e}}+\sqrt{Q_{p}}\right)^{2}-0.061 \sqrt{Q_{e} Q_{p}}
$$

Since $Q_{e}$ is generally small in relation to $Q_{p}$, the second term of the right-hand side of this equation may be neglected. It follows that:

$$
Q_{p}=\left(\sqrt{Q}-\sqrt{Q_{e}}\right)^{2}=\frac{1}{2} m\left(V_{n}-V_{e l}\right)^{2}
$$

Bitter [2] defines then the deformation wear factor $\varepsilon$ as the amount of energy needed to remove one unit volume of material using deformation wear. Therefore the volume eroded by deformation wear $\mathrm{Vol}_{D}$ is given by:

$$
V o l_{D}=\frac{\frac{1}{2} m\left(V_{n}-V_{e l}\right)^{2}}{\varepsilon}
$$

While $V_{n} \leq V_{e l}$, the collision is purely elastic and no erosion occurs, and if $V_{n}>V_{e l}$, the eroded volume is given by $\operatorname{Vol}_{D}$. Equation (5) shows a dependency to the mass of the particle. If many particles impact the substrate with the same characteristics, one can take $m$ as equal to the total impinging mass.

\section{Cutting wear}

According to the description of cutting wear by Finnie [1], Bitter proposed the following mechanism [3] : if impact energy allows the formation of a permanent indentation, the tangential component of the velocity will make that indentation larger and will also pile up material around the crater. The piled up material is then eventually removed by continuous particle impacts (Figure 3). The hypotheses used for the cutting eroded volume calculation are the same as the one used previously. Thus, if plastic deformation occurs for an acute angle, one also has a shear stress due to the tangential velocity $V_{t}$, applied to the surface $A_{x}$ of the particle section which has penetrated into the substrate. Finnie [1] or Arabnejad et al. [6] define the eroded

Page 3 of 8 volume $\mathrm{Vol}_{C}$ as the volume swept by the surface $A_{x}$ during the collision time. Hence, defining $x_{c}$ the abscissa where cutting stops, $\mathrm{Vol}_{C}$ can be calculated as:

$$
\operatorname{Vol}_{C}=\int_{0}^{x_{c}} A_{x} d x
$$

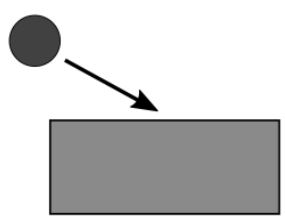

(a)

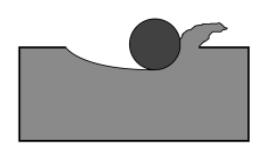

(b)

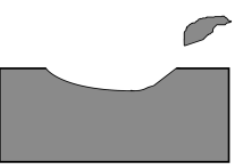

(c)
Figure 3: Schematic of cutting erosion procedure - (a) before the impact, (b) crater formation and piling material, (c) separation of material from the surface - Adapted from Parsi et al. [13]

In order to obtain an expression of the surface $A_{x}$, equations of the particle motion originally developed by Finnie et al. [1] can be resolved:

$$
\begin{aligned}
& m \frac{d^{2} x}{d t^{2}}+P . A_{x}=0 \\
& m \frac{d^{2} y}{d t^{2}}+P . A_{y}=0
\end{aligned}
$$

Where $P$ is the impact pressure which is assumed to be equal to the material hardness [6]. The area $A_{y}$ can be geometrically calculated from the contact area radius $r_{y}$, which can be expressed using the indentation depth $y$ and the particle radius $R$ :

$$
A_{y}=\pi r_{y}^{2}=2 \pi y R
$$

Then, parameter $K$ is introduced as the ratio of the projected surface $A_{y}$ to the projected surface $A_{x}$ (Figure 4). The equations become:

$$
\begin{aligned}
& m \frac{d^{2} x}{d t^{2}}+\frac{P 2 \pi R}{K} y=0 \\
& m \frac{d^{2} y}{d t^{2}}+P 2 \pi R y=0
\end{aligned}
$$

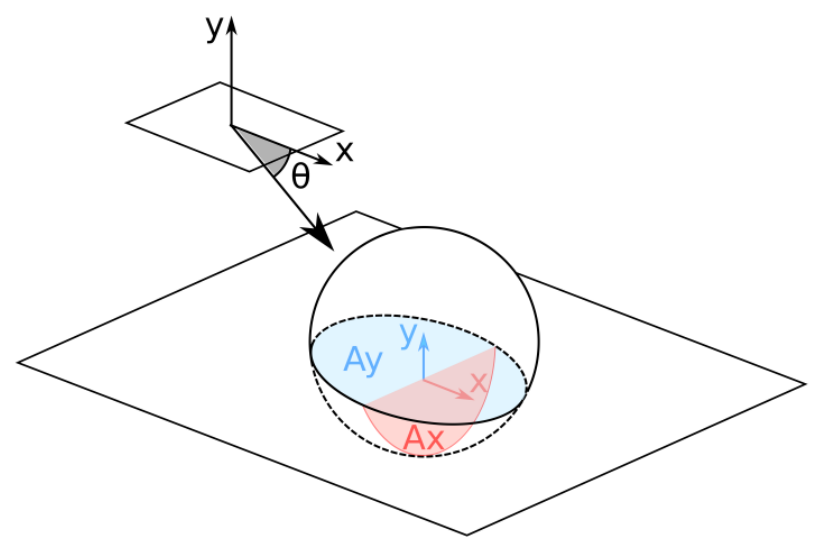

Figure 4: Schematic of the projected surface $A_{x}$ and $A_{y}$ 
The y-projected equation has the following type of solution:

$$
y(t)=A \cos (\beta t)+B \sin (\beta t)
$$

Where $\beta=\sqrt{\frac{2 \pi R P}{m}}$. At the beginning of the impact the coordinates of the contact point are $x(0)=0$ and $y(0)=0$. Additionally $x^{\prime}(0)=$ $V \cos (\theta)$ and $y^{\prime}(0)=V \sin (\theta)$. Thus:

$$
y(t)=\frac{V \sin (\theta)}{\beta} \sin (\beta t)
$$

And:

$$
x(t)=t V \cos (\theta)-V \sin (\theta)\left(\frac{\beta t-\sin (\beta t)}{K \beta}\right)
$$

$\mathrm{Vol}_{C}$ is calculated by:

$$
\operatorname{Vol}_{C}=\int_{0}^{x_{c}} A_{x} d x=\int_{0}^{t_{c}} \frac{A_{y}}{K} x^{\prime}(t) d t=\int_{0}^{t_{c}} \frac{2 \pi R}{K} y(t) x^{\prime}(t) d t
$$

Which can be developed as:

$$
\begin{aligned}
\operatorname{Vol}_{C}=\frac{2 \pi R}{K} \frac{V^{2} \sin (\theta) \cos (\theta)}{\beta^{2}}\left(1-\cos \left(\beta t_{c}\right)\right) \\
+\frac{2 \pi R}{K^{2}} \frac{V^{2} \sin ^{2}(\theta)}{\beta^{2}}\left(\cos \left(\beta t_{c}\right)-1\right) \\
+\frac{\pi R}{K^{2}} \frac{V^{2} \sin ^{2}(\theta)}{2 \beta^{2}}\left(1-\cos \left(2 \beta t_{c}\right)\right)
\end{aligned}
$$

Where $t_{c}$ is the time when the cutting action stops. According to Finnie [1] and Arabnejad et al. [6], two scenarios exist when $t=t_{c}$ :

1) The particle cannot move forward and is trapped into the substrate : $x^{\prime}\left(t_{c}\right)=0$

2) The particle leaves the surface : $y\left(t_{c}\right)=0$

Whereas the first scenario corresponds to quasi-normal angle impact, the second one corresponds to low angle impact. The critical angle $\theta_{c}$ between the two scenarios is given by the boundary condition:

$$
\begin{aligned}
& x^{\prime}\left(t_{c}\right)=0=V \cos (\theta)-\frac{V \sin (\theta)}{K}\left(1-\cos \left(\beta t_{c}\right)\right) \\
& \Leftrightarrow \cos \left(\beta t_{c}\right)=1-\frac{K}{\tan (\theta)} \\
& \Rightarrow-1 \leq 1-\frac{K}{\tan (\theta)} \leq 1 \Rightarrow \theta \geq \arctan \left(\frac{K}{2}\right)
\end{aligned}
$$

While the impinging angle $\theta$ is lower than the critical angle $\theta_{c}=$ $\arctan \left(\frac{K}{2}\right)$, the particle leaves the subtract with a non-null tangential velocity, and while $\theta$ is above $\theta_{c}$, the particle is stuck in the subtract at the end of the cutting action.

The volume eroded by cutting action $\operatorname{Vol}_{C}$ is calculated using the ideal hypothesis that each impact would remove this volume. To take into account the fact that several impacts are usually required to remove a piece of material the cutting erosion efficiency $C$ is introduced. Finally, the two conditions on the particle behavior give the following expressions for $\mathrm{Vol}_{c}$ :

$\operatorname{Vol}_{C}=\left\{\begin{array}{c}C \times \frac{m V^{2} \cos ^{2}(\theta)}{2 P}, \quad \text { for } \theta \geq \theta_{c} \\ C \times \frac{2 m V^{2} \sin (\theta)(K \cos (\theta)-\sin (\theta))}{K^{2} P}, \quad \text { for } \theta<\theta_{c}\end{array}\right.$

As for the deformation wear calculation, if many particles impact the substrate, $m$ can be taken as equal to the total impinging mass.

\section{Erosion ratio}

Trontin et al. [11] [12], as well as Arabnejad et al. [6] define the erosion ratio as the subtract eroded mass rate divided by the particle impinging mass rate. Also, one can calculate the erosion rate $\eta_{e r}$ as follows:

$$
\eta_{e r}=F_{S} \rho \frac{V_{o l}+V_{o} l_{D}}{m}
$$

Where $F_{s}$ is the particle sharpness factor, $\rho$ is the material density, and $m$ the particle total impinging mass. Table 1 summarizes the different expressions used to calculate the erosion mass rate.

Table 1: Expressions used for erosion rate calculation

\begin{tabular}{|l|c|c|}
\hline & Deformation & Cutting \\
\hline$V_{n}<V_{e l}$ & 0 & 0 \\
\hline $\begin{array}{l}V_{n}>V_{e l} \\
\text { and } \theta \geq \\
\theta_{c}\end{array}$ & $\frac{\frac{1}{2} m\left(V \sin (\theta)-V_{e l}\right)^{2}}{\varepsilon}$ & $\frac{m C V^{2} \cos ^{2}(\theta)}{2 P}$ \\
\hline $\begin{array}{l}V_{n}>V_{e l} \\
\text { and } \theta< \\
\theta_{c}\end{array}$ & $\frac{\frac{1}{2} m\left(V \sin (\theta)-V_{e l}\right)^{2}}{\varepsilon}$ & $\frac{2 m C V^{2} \sin (\theta)(K \cos (\theta)-\sin (\theta))}{K^{2} P}$ \\
\hline
\end{tabular}

Several input variables are needed to be characterized in the ice crystals context:

- Arabnejad et al. [6] assume that particle sharpness changes the erosion effectiveness through stress concentration. Since the eroded volume calculated in this paper use the hypothesis of spherical particles, this volume has to be corrected in the case of sharp particles using the sharpness factor $F_{S}$. Based on experimental observations the eroded volume is up to 4 times higher for fully sharp particles. Thus the sharpness factor $F_{S}$ introduced above varies between 1 for fully rounded particles up to 4 for fully sharp particles. Since the NRC RATFac experimentations use ice crystal produced from a grinder one can consider the particle as highly sharped. A value of 4 is taken for the sharpness factor for RATFac experimentations simulations.

- According to Arabnejad et al. [6], the impact pressure $P$ is equal to the material hardness. However, it is complicated to obtain a precise hardness value for ice crystal accretion as few data are available. Chuzel [14] shows that ice hardness double between $-10^{\circ} \mathrm{C}$ and $50^{\circ} \mathrm{C}$, and Poirier et al. [15] give experimental measures of ice hardness represented by the following expression: $P(T)=$

Page 4 of 8 
$(-0.6 \pm 0.4)(T-273.15)+(14.7 \pm 2.1)$. However, according to the author this equation is questionable for a temperature of $0^{\circ} \mathrm{C}$. Moreover the ice layer used for these measurements is not produced by accretion process which can affect the mechanical behavior of the ice.

- The ratio of projected area $K$ is given by Arabnejad et al. [6] for sand grain application (sharp particle) as $K_{\text {grain }} \approx 0.4$. Moreover, according to Arabnejad et al., one has geometrically: $K_{\text {sphere }} \approx$ $2.5 K_{\text {grain }}$. Thus $K=K_{\text {sphere }}=1$ in the presented model, where particles are assumed spherical $(K=1$ even for sharp particles: the sharpness factor will correct the calculated volumes in the case of sharp particles).

- Regarding $V_{e l}$ calculation, ice elastic limit is given by Chuzel [14] for atmospheric ice accretion with a value of $R_{e l}=12 \mathrm{MPa}$. Polycrystalline ice Young modulus and Poisson coefficient are given by Chuzel [14] and confirmed by Petrovic [16]: $E=10 G P a$ and $q=$ 0.3 . Such values produce a very small $V_{e l}$ and every impact will fulfill the erosion triggering condition $V_{n}>V_{e l}$.

- Finally the model has two empirical factors which are not characterized in the literature for ice crystal accretion: the deformation wear factor $\varepsilon$ and the cutting efficiency $C$. These parameters are calibrated using Currie et al. experiments [7] [8]. However one can use at first approximation the $\varepsilon$ expression given by Arabnejad et al. for cement [6] which is composed by particle agglomerations as may also be accreted ice: $\varepsilon=F_{\varepsilon} R_{e l}^{2} / E$, where $F_{\varepsilon}$ is a calibrated constant. The calibration gives : $C=0.3$ and $F_{\varepsilon}=$ $1.53 \times 10^{5}$.

\section{Results}

This section shows the simulation results of Run 17 (Figure 5) and Run 233 (Figure 7) from Currie et al. experimental series realized at the NRC [8]. These series use an icing tunnel located in an altitude chamber (Research Altitude Test Facility or RATFac). The model presented in this paper does not take into account the amount of liquid water. In order to compare the model with experimental data, it is then necessary to compute a case with low crystal melting ratio such as Run 17 (with $6 \%$ of melting ratio) or Run 233 (with $8.6 \%$ of melting ratio). The difference between these two Run is the Mach number which is 0.25 for Run 17 and 0.40 for Run 233. Table 2 presents a summary of the experimental conditions used for these two Runs.

Table 2: NRC experimental conditions for Run 17 and 233 Mach number M, total water content TWC, total pressure Pt, mean volume diameter MVD, melting ratio Yl

\begin{tabular}{|l|l|l|l|l|l|}
\hline Run & M & TWC & Pt & MVD & Yl \\
\hline 17 & 0.25 & $6 \mathrm{~g} / \mathrm{m}^{3}$ & $34.5 \mathrm{kPa}$ & $45 \mu \mathrm{m}$ & $6 \%$ \\
\hline 233 & 0.40 & $6 \mathrm{~g} / \mathrm{m}^{3}$ & $34.5 \mathrm{kPa}$ & $45 \mu \mathrm{m}$ & $8.6 \%$ \\
\hline
\end{tabular}

The result presented Figure 5 shows correctly computed ice shape for Run 17 using the semi-empirical model presented in this paper. The two models (HAIC and the presented model called Sim) give very Page 5 of 8 high accuracy since they are both calibrated with the NRC experimental series of low Mach number to which Run 17 belongs.

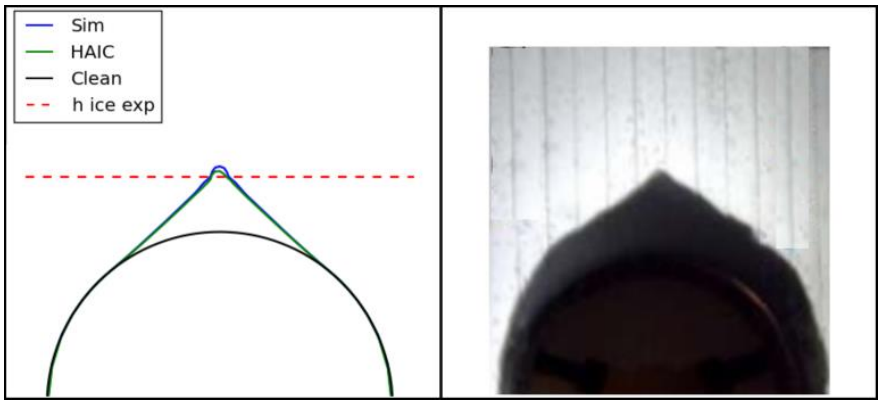

Figure 5: Run 17 ice shape simulation (left) and experimental observation (right) [8] - Comparison between Trontin et al. HAIC empirical model, presented semi-empirical model (Sim), and experimental data ice height measurment (red dash)

Figure 6 shows the contribution of deformation erosion and cutting erosion in $\eta_{e r}$ calculation. One can notice that cutting erosion is higher than deformation erosion which is negligible except near the stagnation point where impacts occur mostly with very small tangential velocity.

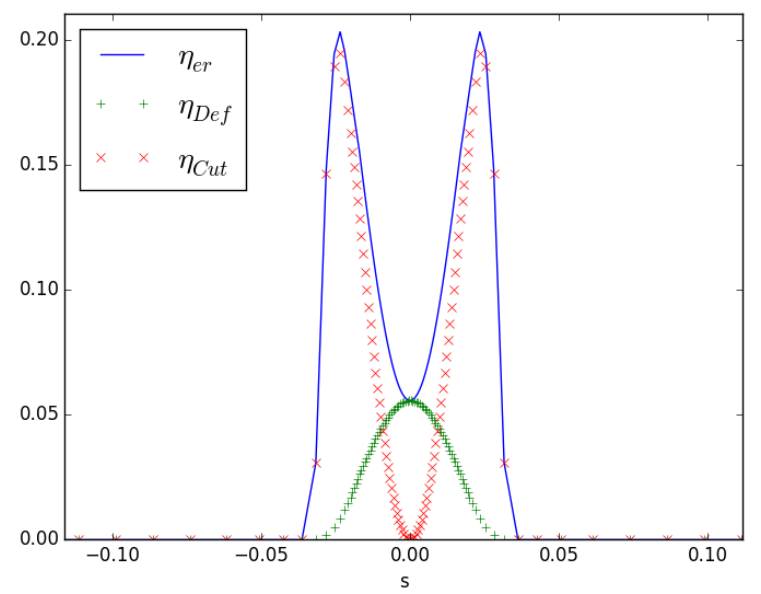

Figure 6: Erosion rate along the curvilinear abscissa of the studied profile (stagnation point at $s=0$ ) - Deformation component ( $\left.\eta_{\text {Def }}\right)$ and Cutting component $\left(\eta_{\text {Cut }}\right)$

Run 233 results presented on Figure 7 is also in good agreement with experimental data. Ice height is better predicted using the semiempirical model than HAIC's one. This simulation shows the capability of the presented model to predict ice shapes for higher Mach number. 


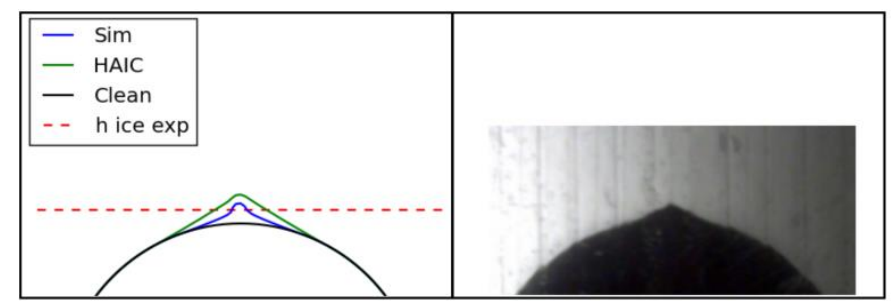

Figure 7: Run 233 ice shape simulation (left) and experimental observation (right) [8] - Comparison between Trontin et al. HAIC empirical model, presented semi-empirical model (Sim), and experimental data ice height measurement (red dash)

The main differences and similarities between the empirical HAIC model and the semi-empirical model presented in this paper are the following: both HAIC and semi-empirical model have a squared velocity dependency, which underline the main kinetic energy dependence of the erosion mechanism. However, whereas HAIC model only consider the tangential component of the particle velocity, the presented model considers also the normal velocity contribution. This allows the simulation to predict the smoothed profile near the stagnation point without using numerical correction (curvature dependent term of the HAIC model). Moreover, the semiempirical model has no liquid water dependency and is not able to predict the erosion rate for high melting ratio cases, while HAIC model is operational for these cases using an empirical function to take into account the amount of liquid water trapped in the ice layer. Finally, these two models use calibration based on $45 \mu \mathrm{m}$ MVD particles and ice shape are not correctly simulated when the particle size is lowered while keeping the same impingement rate. Thus, one should improve the presented model implementing particle size and liquid water dependency.

\section{Sensitivity study}

In order to obtain an idea of the impact of the model parameters on the erosion rate, Figure 8 presents ice shapes obtained for Run 17 using set of parameters represented in Table 3 . This sensitivity study is not exhaustive but allows us to know in first approximation which kind of influence have these parameters.

Table 3: Parameters value for the sensitivity study (wall temperature is $273.15 \mathrm{~K}$ )

\begin{tabular}{|l|l|l|l|l|l|}
\hline & $50 \%$ & $75 \%$ & $\begin{array}{l}100 \% \\
\text { (Ref) }\end{array}$ & $125 \%$ & $150 \%$ \\
\hline$C$ & 0.15 & 0.23 & 0.3 & 0.38 & 0.45 \\
\hline$P$ & $7.35 \mathrm{MPa}$ & $11.0 \mathrm{MPa}$ & $14.7 \mathrm{MPa}$ & $18.4 \mathrm{MPa}$ & $22.1 \mathrm{MPa}$ \\
\hline$\varepsilon$ & $92.3 \mathrm{MJ} / \mathrm{m}^{3}$ & $139 \mathrm{MJ} / \mathrm{m}^{3}$ & $185 \mathrm{MJ} / \mathrm{m}^{3}$ & $231 \mathrm{MJ} / \mathrm{m}^{3}$ & $277 \mathrm{MJ} / \mathrm{m}^{3}$ \\
\hline$R_{e l}$ & $1.74 \mathrm{MPa}$ & $2.61 \mathrm{MPa}$ & $3.47 \mathrm{MPa}$ & $4.34 \mathrm{MPa}$ & $5.21 \mathrm{MPa}$ \\
\hline$K$ & 0.50 & 0.75 & 1.00 & 1.25 & 1.50 \\
\hline
\end{tabular}

Each simulation has the reference value of all parameters but the one studied which varies between $50 \%$ and $150 \%$ of the reference value. Values of $R_{e l}$ and $P$ are calculated for a temperature of $273.15 \mathrm{~K}$ which is the temperature of the accreted ice in Run 17 conditions (presence of liquid water).

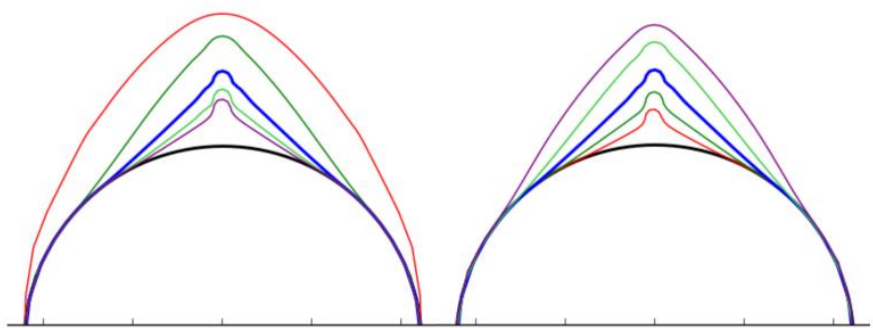

(a) : C

(b) : P

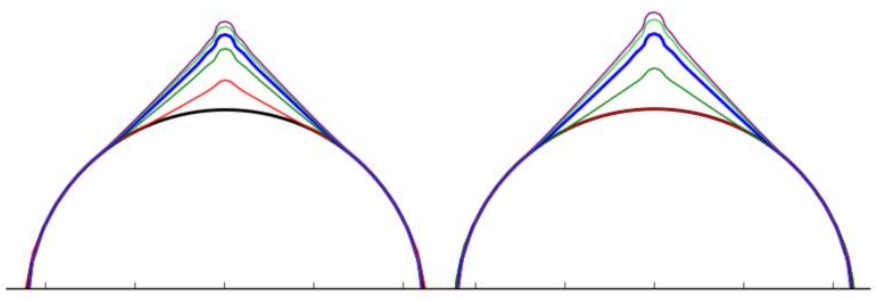

(c) $: \varepsilon$

(d) : Rel
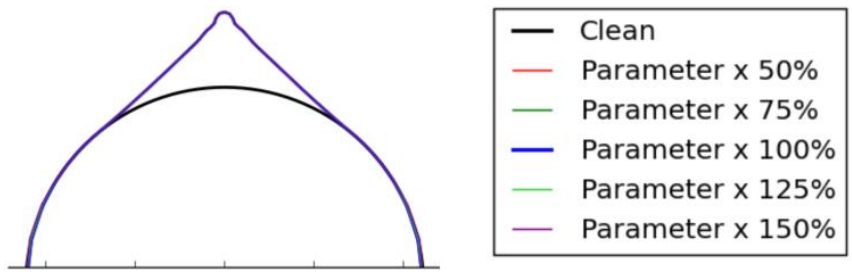

(e) : K

Figure 8: Run 17 ice shape using different values of parameter $C$ (a), $P(\mathbf{b}), \varepsilon(\mathrm{c}), \boldsymbol{R}_{e l}(\mathrm{~d}), \mathrm{K}(\mathrm{e})$

(a) The cutting efficiency $C$ has a high influence on ice shape. When its value increase one can easily notice the increase of eroded material, with a lower influence near the stagnation point where the tangential velocity is negligible. Secondly, increasing the volume eroded by cutting action also decreases the length of the iced surface.

(b) The impact pressure $P$ has also a direct influence on the volume eroded by cutting action. Ice shape evolution with $P$ is as important as the one with $C$.

(c) The deformation wear factor $\varepsilon$ influences the volume eroded by deformation wear which is not as significant as the volume eroded by cutting wear.

(d) The elastic limit $R_{e l}$ takes action in $V_{e l}$ calculation (equation 4), which remains very small compared to $V_{n}$, and in $\varepsilon$ calculation where it appears squared. Thus ice shape evolution with $R_{e l}$ is similar to the one with $\varepsilon$ but amplified.

(e) The ratio of projected area $K$ has an influence on the calculation of the limit angle between quasi-normal impact and low angle impact. When $K$ varies from 0.5 to $1.5, \theta_{c}$ varies from $14^{\circ}$ to $37^{\circ}$, which means that the majority of the impacts are occurring with a quasi-normal angle. The value of $K$ defines the area where the impact angle is considered as quasi-normal and also the value of the volume eroded in the case of low impact angle (equation $6)$. For the variation of $K$ considered here, there is no influence on ice shape since almost all impacts are

Page 6 of 8 
considered as quasi-normal. In order to characterize $K$ influence, simulations with lower impact angle have to be performed.

The majority of these parameters have great influence on ice shape. In addition, their characterization is not an easy work regarding large number of phenomena and coupled dependencies in the accretion process which complicates the feasibility of experimentations as well as the understanding of their observation.

\section{Further work}

\section{Liquid water dependency}

Currie et al. [8] experimental study shows that above a certain value, icing severity decreases with increasing ice crystal melting ratio (right section of the melting ratio plateau effect shown Figure 9).

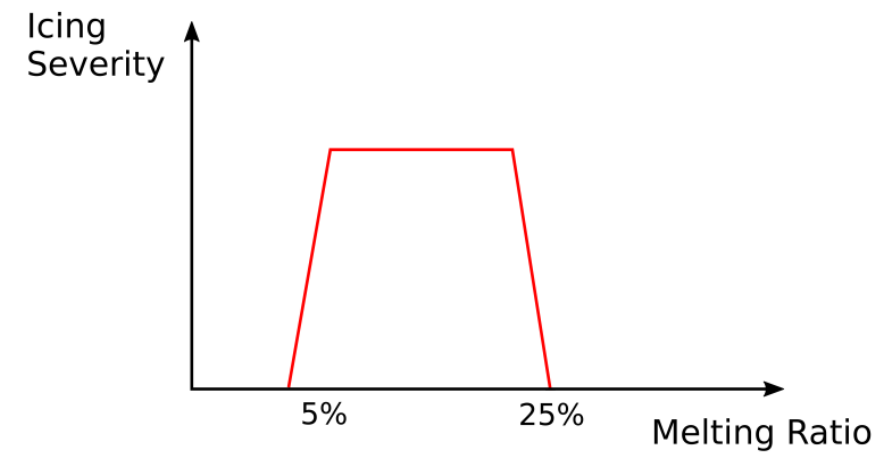

Figure 9: Evolution of icing severity versus liquid water to total water content - Adapted from Currie et al. [8]

As a matter of fact the presence of liquid water is very essential for the accretion process in ice crystal condition. Inside jet engines, while none melt ice crystal would rebound to the surfaces, the liquid water of a partially melt ice crystal enable it to stick to the wall and begin the accretion process. However, the ice severity is dropping when the liquid ratio is too high. Too few liquid water on the wall prohibits the sticking of solid particles, while too few ice particles is not enough to cool the surface sufficiently and are then quickly washed away by the liquid water. Trontin et al. erosion empirical model takes this dependency into account [12], which is not the case of the presented semi-empirical model. Thus, the model presented in this paper is not able to predict ice accretion with a high liquid ratio.

\section{Particle size dependency}

An important weakness of the semi-empirical model presented in this paper lies in the fact that it is not particle size dependent. This means that, the calculated erosion rate is the same if numerous small particle impacts or few large particle impacts as long as impingement mass flux rates are the same. This hypothesis is not realistic and should be reviewed since, based on experimental evidences, several authors agree on the particle size dependency of erosion rate. Regarding sand erosion studies, Oka et al. [17], Arabnejad et al. [6], and Parsi et al. [13] show that erosion rate usually increase with particle size considering constant impingement rate. Knezevici et al. [18] [19] noticed the same effect for ice crystal accretion. An essential step to improve the erosion model is to implement this particle size effect in the calculation and/or the characterization of the model parameters.

Page 7 of 8

\section{Summary/Conclusions}

Erosion rate calculations for ice crystal accretion simulations are usually based on empirical modelling. This study is a first step to provide a more reliable model using the solid/solid collision theory to leverage a semi-empirical model. This theory is mainly built on Finnie et al. [1] and Bitter [2] [3] studies, which assume that two main mechanisms are responsible for the erosion caused by solid impacts: the deformation wear and the cutting wear. The model developed is able to predict ice crystal erosion rate with good agreement for NRC's low liquid water to total water content cases. It still has to be assessed using larger databases, especially to take into account the presence of the liquid water, as well as the particle size effect, which have been shown to have significant impact on erosion and accretion phenomena.

\section{References}

[1] I. Finnie and D. McFadden, "On the velocity dependence of the erosion of ductile metals by solid particles at low angles of incidence," Wear, 1978.

[2] J. Bitter, "A study of erosion phenomena - Part I," Koninklijke, Shell-Laboratorium, Amsterdam, 1962.

[3] J. Bitter, "A study of erosion phenomena - Part II," Koninklijke, Sheil-Laboratorium, Amsterdam, 1962.

[4] I. Hutchings, "A model for the erosion of metals by sherical particles at normal incidence," University of Cambridge, Department of Metallurgy and Materials Science, 1981.

[5] C. Huang, S. Chiovelli, P. Minev, J. Luo and K. Nandakumar, "A comprehensive phenomenological model for erosion of materials in jet flow," Powder Technology, 2008.

[6] H. Arabnejad, A. Mansouri, S. Shirazi and B. McLaury, "Development of mechanistic erosion equation for solid particles," Wear, 2015.

[7] T. C. Currie and D. Fuleki, "Experimental Results for Ice Crystal Icing on Hemispherical and Double Wedge Geometries at Varying Mach Numbers and Wet Bulb Temperatures," 8th AIAA - Atmospheric and Space Environments Conference, 2016.

[8] T. C. Currie, D. Fuleki and A. Mahallati, "Experimental Studies of Mixed-Phase Sticking Efficiency for Ice Crystal Accretion in Jet Engine," 6th AIAA - Atmospheric and Space Environments Conference, 2014.

[9] J. Walter Strapp, Jeanne G. Mason and Philip Chow, "The Ice Particle Threat to Engines in Flight," AIAA, 2006.

[10] E. Commission, "MUSIC-haic," H2020, [Online]. Available: https://ec.europa.eu/inea/en/horizon-2020/projects/h2020transport/aviation/music-haic. [Accessed November 2018]. 
[11] P. Villedieu, P. Trontin and R. Chauvin, "Glaciated and mixedphase ice accretion modeling using ONERA 2D icing suite," 6th AIAA - Atmospheric and Space Environments Conference, 2014.

[12] A. Baumert, S. Bansmer, P. Trontin and P. Villedieu, "Experimental and numerical investigations on aircraft icing at mixed phase conditions," International Journal of Heat and Mass Transfer, 2018.

[13] E. Commission, "HAIC," 2013-2016. [Online]. Available: http://www.haic.eu/. [Accessed 2018].

[14] M. Parsi, K. Najmi, F. Najafifard, S. Hassani, B. S. McLaury and S. A. Shirazi, "A comprehensive review of solid particle erosion modeling for oil and gas wells and pipelines applications," Journal of Natural Gas Science and Engineering, 2014.

[15] Y. Chuzel, "Caractérisation expérimentale et simulation numérique d'impacts de glace à haute vitesse," Institut National des Sciences Appliquées de Lyon, Lyon, 2008.

[16] L. Poirier, E. P. Lozowski and R. I. Thompson, "Ice hardness in winter sports," Cold Regions Science and Technology, 2011.

[17] J. Petrovic, "Mechanical properties of ice and snow," Journal of Materials Science, 2003.

[18] Y. Oka, K. Okamura and T. Yoshida, "Practical estimation of erosion damage caused by solid particle impact - Part 1 : Effects of impact parameters on a predictive equation," Wear, 2005.
[19] D. C. Knezevici, D. Fuleki, T. C. Currie, B. Galeote, J. Chalmers and J. MacLeod, "Particle Size Effects on Ice Crystal Accretion - Part II," 5th AIAA - Atmospheric and Space Environments Conference, 2013.

[20] D. C. Knezevici, D. Fuleki, T. C. Currie and J. MacLeod, "Particle Size Effects on Ice Crystal Accretion," 4th AIAA Atmospheric and Space Environments Conference, 2012.

[21] L. Landau and E. Lifshitz, Theory of elasticity - second edition, Pergamon Press, 1970.

[22] D. Georgiou and G. Paleos, "The Particle-Wall, Normal-Impact Collision Coefficient in the Presence of a Liquid Film," The American Society of Mechanical Engineers, 1990.

\section{Acknowledgement}

This work is conducted in cooperation between ONERA and SAFRAN AIRCRAFT ENGINES (Safran Group). The authors gratefully acknowledge the ANRT (Association Nationale de la Recherche et de la Technologie) which supports part of the PhD.

\section{Contact Information}

Virgile Charton

Phd student - Safran Aircraft Engines YXTA / Onera DMPE-MH virgile.charton@onera.fr 